\title{
Association between unilateral or bilateral mastectomy and breast cancer death in patients with unilateral ductal carcinoma
}

This article was published in the following Dove Press journal:

Cancer Management and Research

16 November 2017

Number of times this article has been viewed

\section{Shailesh Agarwal' \\ Lisa Pappas ${ }^{2}$ \\ Jayant Agarwal ${ }^{3}$}

'Department of Surgery, University of Michigan, Ann Arbor, MI, ${ }^{2}$ Huntsman Cancer Institute, Biostatistics Core, ${ }^{3}$ Department of Surgery, Division of Plastic Surgery, University of Utah, Salt Lake City, UT, USA
Correspondence: Jayant Agarwal Department of Surgery, Division of Plastic Surgery, University of Utah, $50 \mathrm{~N}$ Medical Dr., Salt Lake City, UT, USA Email Jay.agarwal@hsc.utah.edu
Background: Utilization of bilateral mastectomy for unilateral breast cancer is increasing despite cost and surgical risks with conflicting reports of survival benefit. Current studies evaluating death after bilateral mastectomy have included patients treated both with breast conservation therapy and unilateral mastectomy. In this study, we directly compared breast cancer-specific death of patients who underwent bilateral or unilateral mastectomy for unilateral breast cancer using a matched cohort analysis.

Methods: This was an observational study of women diagnosed with unilateral breast cancer from 1998 through 2002, using the Surveillance, Epidemiology, and End Results (SEER) database. A 4-to-1 matched cohort of patients was selected including 14,075 patients. Mortality of the groups was compared using Cox proportional hazards models for cause-specific death. Results: A total of 41,510 patients diagnosed with unilateral breast cancer were included. Unilateral mastectomy was performed in $93 \%$ of patients, while bilateral mastectomy was performed in the remaining $7 \%$ of patients. When 4-to-1 matching was performed, 11,260 unilateral mastectomy and 2,815 bilateral mastectomy patients were included. Patients with bilateral mastectomy did not have a significantly lower hazard of breast cancer-specific death when compared with patients with unilateral mastectomy (hazard ratio: 0.92 vs $1.00, p=0.11$ ). Conclusion: Bilateral mastectomy did not provide a clinically or statistically significant breast cancer-specific mortality benefit over unilateral mastectomy based on a matched cohort analysis of a nationwide population database. These findings should be interpreted in the context of patient preference and alternative benefits of bilateral mastectomy.

Keywords: breast cancer, contralateral prophylactic mastectomy, bilateral mastectomy, survival, logistic regression, matched cohorts

\section{Introduction}

Over the past decade, utilization of bilateral mastectomy for unilateral breast cancer has increased. ${ }^{1-3}$ This may be attributed to a multitude of factors including fear of developing another breast cancer, the use of highly sensitive diagnostic modalities such as magnetic resonance imaging, improved diagnosis of hereditary breast cancer as in patients with $B R C A$ mutations, and improved access to breast reconstruction. ${ }^{1,2,4-12}$ However, bilateral mastectomy is an extensive surgical procedure which often results in longer inpatient hospital stays, higher transfusion rates, and increased reoperation rates. ${ }^{13-15}$ The risks traditionally associated with unilateral breast reconstruction may be compounded in patients undergoing bilateral reconstruction. ${ }^{13,15}$ Additionally, the costs associated with lengthened operative time and inpatient hospital stays are increasingly monitored and must be considered when caring for breast cancer patients. 
Randomized controlled trials comparing survival in patients undergoing bilateral mastectomy with traditional surgical options such as breast conservation therapy (BCT) or unilateral mastectomy have not been performed. Using the Surveillance, Epidemiology, and End Results (SEER) database, several studies have found that patients undergoing bilateral mastectomy have a significant reduction in the adjusted hazard of breast cancer death when compared with those undergoing unilateral mastectomy. ${ }^{3,16,17}$ However, limitations in follow-up duration and in statistical design have led to questions surrounding interpretation of these findings.

In this study, we evaluated breast cancer death using the SEER database with at least 10 years of censored follow-up by performing a matched patient cohort directly comparing bilateral mastectomy with unilateral mastectomy for unilateral breast cancer.

\section{Methods}

\section{Data source}

Case-level deidentified data from 1998 to 2002 were extracted from the SEER cancer database (November 2014 submission) with follow-up and survival cut-off until December 31, 2012. Data accessed from the SEER are publicly available free of charge. This allowed for a minimum 10-year survival analysis. The SEER database is a national effort that collects patient-level data for all index malignant tumors in 18 cancer registries across the USA and captures roughly $28 \%$ of the nation's population. This database is regarded as nationally representative and contains detailed demographic, socioeconomic, oncologic, and treatment information. To ensure data accuracy, chart abstractors undergo extensive training. Malignant tumors are encoded by use of the ninth revision of the International Classification of Diseases for Oncology.

\section{Inclusion/exclusion criteria}

Data were extracted from the SEER database for all female patients with a unilateral, invasive ductal breast cancer (International Classification of Diseases for Oncology code 8500) who underwent unilateral or bilateral mastectomy (site-specific surgery codes - unilateral: 41, 43, 44, 45, 46, 51, 53, 54, 55, 56; bilateral: 42, 47, 48, 49, 52, 57, 58, 59, $63,75)$. Patients with unknown stage or histology code other than 8500 were excluded.

\section{Matching methodology}

Patients were matched on three critical variables to account for tumor severity (stage), follow-up time (year of diagnosis), and age at diagnosis. Exact matching for stage and year of diagnosis were performed, and Mahalanobis-metric matching method was used for age of diagnosis. The result was a 4-to-1 matched cohort sample.

\section{Statistical analysis}

Pre-matched and post-matched absolute standard differences of patient characteristics were compared to assess covariance balance. Additionally, pre- and post-matched groups were compared using chi-square tests for categorical factors and Wilcoxon tests for continuous factors. Associations of breast cancer-specific death with unilateral versus bilateral mastectomy were assessed with adjusted and unadjusted Cox proportional hazards models. Breast cancer-specific death was defined as death caused by breast cancer. Stage, age at diagnosis, and year of diagnosis were included to account for the cluster effect in the matched data.

\section{Results}

\section{Patient characteristics (pre-matching)}

A total of 41,510 patients were diagnosed with unilateral, invasive breast cancer, stage I-IV, from 1998 through 2002. A majority of patients underwent unilateral mastectomy $(n=38,596 ; 93.0 \%)$. There were statistically significant differences between patients who underwent unilateral and bilateral mastectomy with respect to year of diagnosis, tumor stage, age at diagnosis, race, nodal involvement, tumor size, tumor grade, and breast reconstruction status $(p<0.005$ for each covariate; Table 1).

\section{Patient characteristics (post-matching)}

Patient matching was performed using year of diagnosis, tumor stage, and age at diagnosis (Table 2). Matching on year of diagnosis allowed for well-balanced follow-up time. After matching, the original 2,815 (20\%) patients who underwent bilateral mastectomy were included with 11,260 $(80 \%)$ patients who underwent unilateral mastectomy. In the post-match analysis, patient characteristics including nodal involvement, tumor size, tumor grade, and reconstruction status remained significantly different (Table 2). However, overall imbalance between the two cohorts improved substantially with absolute standardized differences (\%) below $0.4 \%$ for all factors.

\section{Bilateral mastectomy is not independently associated with adjusted breast cancer- specific death}

Kaplan-Meier survival analysis showed that patients treated with bilateral mastectomy had improved "unadjusted" breast 
Table I Pre-match patient characteristics

\begin{tabular}{|c|c|c|c|c|}
\hline Characteristics & $\mathbf{N}$ & Bilateral \% (n) & Unilateral \% (n) & Test statistic \\
\hline & & $N=2,815$ & $N=38,695$ & \\
\hline Year of diagnosis & 41,510 & & & $\chi_{4}^{2}=150.74, p<0.001$ \\
\hline 1998 & & 7 (204) & $12(4,808)$ & \\
\hline 1999 & & $9(261)$ & $12(4,686)$ & \\
\hline 2000 & & $22(630)$ & $25(9,753)$ & \\
\hline 2001 & & $30(834)$ & $26(9,975)$ & \\
\hline 2002 & & 31 (886) & $24(9,473)$ & \\
\hline Stage & 41,510 & & & $\chi_{3}^{2}=104.39, p<0.001$ \\
\hline I & & 43 (I 197) & $35(13,386)$ & \\
\hline$\| \mathrm{A}$ & & $27(752)$ & $26(10,119)$ & \\
\hline IIB & & $12(330)$ & $14(5,566)$ & \\
\hline IIIA & & $10(293)$ & $12(4,782)$ & \\
\hline IIIB & & $2(67)$ & $3(1,273)$ & \\
\hline IIIC & & $5(132)$ & $6(2,400)$ & \\
\hline IIINOS & & $0(9)$ & I (206) & \\
\hline IV & & I (35) & $2(959)$ & \\
\hline Age at diagnosis $(y)$ & 41,510 & $51(43,59)$ & $49(59,72)$ & $F_{1.41509}=840.69, p<0.001$ \\
\hline Race & & & & $\chi_{3}^{2}=158.88, p<0.001$ \\
\hline White & 41,510 & $90(2,532)$ & $80(31,079)$ & \\
\hline Black & & $5(146)$ & $10(3,896)$ & \\
\hline Other & & $5(|3|)$ & $9(3,626)$ & \\
\hline Unknown & & $0(6)$ & $0(94)$ & \\
\hline Node involvement & & & & $\chi_{2}^{2}=59.82, p<0.001$ \\
\hline 0 nodes & 41,510 & $56(1,566)$ & $50(19,367)$ & \\
\hline I-3 nodes & & 27 (77I) & $27(10,389)$ & \\
\hline$>3$ nodes & & $17(478)$ & $23(8,939)$ & \\
\hline Tumor size (mm) & 40,607 & $10(17,28)$ & $13(20,32)$ & $F_{1.40605}=163.43, p<0.001$ \\
\hline Tumor size & 41,510 & & & $\chi_{3}^{2}=134.53, p<0.001$ \\
\hline $0-20 \mathrm{~mm}$ & & $53(1,499)$ & $43(16,528)$ & \\
\hline $21-40 \mathrm{~mm}$ & & $32(894)$ & $36(14,083)$ & \\
\hline $4 I+m m$ & & $13(358)$ & $19(7,245)$ & \\
\hline Unknown & & $2(64)$ & $2(839)$ & \\
\hline Grade & 41,510 & & & $\chi_{4}^{2}=15.1 \mathrm{I}, p=0.004$ \\
\hline I & & $13(375)$ & $12(4,522)$ & \\
\hline II & & $37(1,037)$ & $38(14,755)$ & \\
\hline III & & $43(1,211)$ & $44(17,158)$ & \\
\hline IV & & $3(83)$ & $2(850)$ & \\
\hline Unknown & & $4(109)$ & $4(1,4 \mid 0)$ & \\
\hline Reconstruction (yes) & 41,510 & $39(1,104)$ & $13(5,052)$ & $\chi_{1}^{2}=1422.03, p<0.001$ \\
\hline \multicolumn{5}{|l|}{ Receptor status } \\
\hline ER: positive & 41,510 & $6 I(I, 722)$ & $6 \mid(23,5 \mid 5)$ & $\chi_{3}^{2}=6.14, p=0.105$ \\
\hline ER: negative & & $25(696)$ & $24(9,096)$ & \\
\hline ER: borderline & & $0(6)$ & $0(89)$ & \\
\hline ER: unknown & & $14(391)$ & $15(5,995)$ & \\
\hline PR: positive & & $53(1,482)$ & $50(19,429)$ & $\chi_{3}^{2}=13.61, p=0.003$ \\
\hline PR: negative & & $32(907)$ & $32(12,404)$ & \\
\hline PR: borderline & & $0(I I)$ & I (2|7) & \\
\hline PR: unknown & & $15(4 \mid 5)$ & $17(6,645)$ & \\
\hline
\end{tabular}

Abbreviations: ER, estrogen receptor; PR, progesterone receptor. 
Table 2 Post-match patient characteristics

\begin{tabular}{|c|c|c|c|c|}
\hline & $\mathbf{N}$ & Bilateral \% (n) & Unilateral \% (n) & Test statistic \\
\hline & & $N=2,815$ & $N=11,260$ & \\
\hline Year of diagnosis & 14,075 & & & $\chi_{4}^{2}=0, p=1$ \\
\hline 1998 & & 7 (204) & $7(8 \mid 6)$ & \\
\hline 1999 & & $9(26 I)$ & $9(1,044)$ & \\
\hline 2000 & & $22(630)$ & $22(2,520)$ & \\
\hline 2001 & & $30(834)$ & $30(3,336)$ & \\
\hline 2002 & & 31 (886) & $31(3,544)$ & \\
\hline Stage & 14,075 & & & $\chi_{4}^{2}=0, p=1$ \\
\hline I & & $43(1,197)$ & $43(4,788)$ & \\
\hline$\| \mathrm{A}$ & & $27(752)$ & $27(3,008)$ & \\
\hline IIB & & $12(330)$ & $12(1,320)$ & \\
\hline III & & $18(501)$ & $18(2,004)$ & \\
\hline IV & & I (35) & I (I40) & \\
\hline Age at diagnosis $(y)$ & 14,075 & $43(5 \mathrm{I}, 59)$ & $43(51,59)$ & $F_{1.14073}=0.16, p=0.689$ \\
\hline Race & 14,075 & & & $\chi_{3}^{2}=133.86, p<0.001$ \\
\hline White & & $90(2,532)$ & $81(9,112)$ & \\
\hline Black & & $5(146)$ & $12(1,295)$ & \\
\hline Other & & $5(|3|)$ & $7(827)$ & \\
\hline Unknown & & $0(6)$ & $0(26)$ & \\
\hline Node involvement & 14,075 & & & $\chi_{2}^{2}=9.59, p=0.008$ \\
\hline 0 nodes & & $56(1,566)$ & $57(6,445)$ & \\
\hline I-3 nodes & & $27(77 I)$ & $25(2,772)$ & \\
\hline$>3$ nodes & & I7 (478) & $18(2,043)$ & \\
\hline Tumor size (mm) & 13,788 & $10(17,28)$ & $12(19,30)$ & $F_{1.13786}=14.02, p<0.001$ \\
\hline Tumor size & 9,446 & & & $\chi_{2}^{2}=8.55, p<0.014$ \\
\hline $0-20 \mathrm{~mm}$ & & $78(1,499)$ & $75(5,675)$ & \\
\hline $21-40 \mathrm{~mm}$ & & $0(0)$ & $0(0)$ & \\
\hline $4 I+m m$ & & $19(358)$ & $22(1,627)$ & \\
\hline Unknown & & $3(64)$ & $3(223)$ & \\
\hline Grade & 14,075 & & & $\chi_{4}^{2}=30.19, p<0.001$ \\
\hline I & & $13(375)$ & II $(I, 238)$ & \\
\hline II & & $37(1,037)$ & $37(4,122)$ & \\
\hline III & & $43(I, 2 I I)$ & $47(5,256)$ & \\
\hline IV & & $3(83)$ & $2(209)$ & \\
\hline Unknown & & $4(109)$ & $4(435)$ & \\
\hline Reconstruction (yes) & 14,075 & $39(1,104)$ & $2 \mid(2,3 \mid 8)$ & $\chi_{1}^{2}=424.86, p<0.001$ \\
\hline Receptor status & 14,075 & & & \\
\hline ER: positive & & $61(1,722)$ & $60(6,734)$ & $\chi_{1}^{2}=424.86, p<0.001$ \\
\hline ER: negative & & $25(696)$ & $26(2,909)$ & \\
\hline ER: borderline & & $0(6)$ & $0(27)$ & \\
\hline ER: unknown & & $14(391)$ & $14(I, 590)$ & \\
\hline PR: positive & & $53(1,482)$ & $51(5,724)$ & $\chi_{3}^{2}=1.94, p=0.585$ \\
\hline PR: negative & & $32(907)$ & $34(3,789)$ & \\
\hline PR: borderline & & $0(\mathrm{II})$ & I (62) & \\
\hline PR: unknown & & $15(4 \mid 5)$ & I5 $(1,685)$ & \\
\hline
\end{tabular}

Abbreviations: ER, estrogen receptor; PR, progesterone receptor. 
cancer-specific survival when compared with matched patients treated with unilateral mastectomy (Figure 1). "Unadjusted" Cox proportional hazard analysis confirmed that patients who underwent bilateral mastectomy had reduced breast-cancer specific death when compared with matched patients who underwent unilateral mastectomy (hazard ratio [HR] 0.86, $p<0.003$ ).

To adjust for additional demographic and oncologic variables including patient race, estrogen receptor/progesterone receptor (ER/PR) status, radiation therapy, and reconstruction status, adjusted Cox proportional hazard regression analysis comparing the two matched groups was performed. With this model, the estimated death among patients who underwent bilateral mastectomy was not reduced (HR 0.92, 95\% confidence interval $[95 \% \mathrm{CI}]:(0.83,1.02), p=0.11$; Table 3$)$.

\section{Discussion}

In this population-based study, we utilized the National Cancer Institute (NCI) SEER database to compare cause-specific death in patients who underwent bilateral mastectomy and unilateral mastectomy for unilateral breast cancer. Using a 4-to-1 matched cohort of patients diagnosed with unilateral breast cancer from 1998 to 2002, we found no statistically significant improvement in the hazard of breast cancer death among patients who underwent bilateral mastectomy.
In our analysis, we matched the unilateral and bilateral mastectomy cohorts based on three key variables - tumor stage, patient age, and year of diagnosis. These variables were selected so that patients would be matched on variables which can influence decision-making (tumor stage), length of follow-up (year of diagnosis), and overall health condition (age). Further adjustments were included in an effort to account for covariate imbalance between the groups or because these variables such as race or reconstruction status have been previously shown to clinically associate with survival. ${ }^{18,19}$ Although in aggregate there were over 13 times as many patients who underwent unilateral mastectomy as those who underwent bilateral mastectomy, matching was performed for each individual patient with exact matching for stage and year of diagnosis. Therefore, the largest consistent representative match that could be obtained was a 4-to-1 match. Our table indicates that post-matched samples achieved good balance between groups.

Using the SEER database to study patients diagnosed with unilateral breast cancer between 1998 and 2003 with censored follow-up through 2005, Bedrosian et al found a statistically significant reduction in the adjusted hazard of breast cancer death in patients who underwent bilateral mastectomy when compared with patients who underwent unilateral mastectomy $(0.84$ vs $1.0,95 \%$ CI $[0.76,0.92]) .{ }^{16}$ These findings

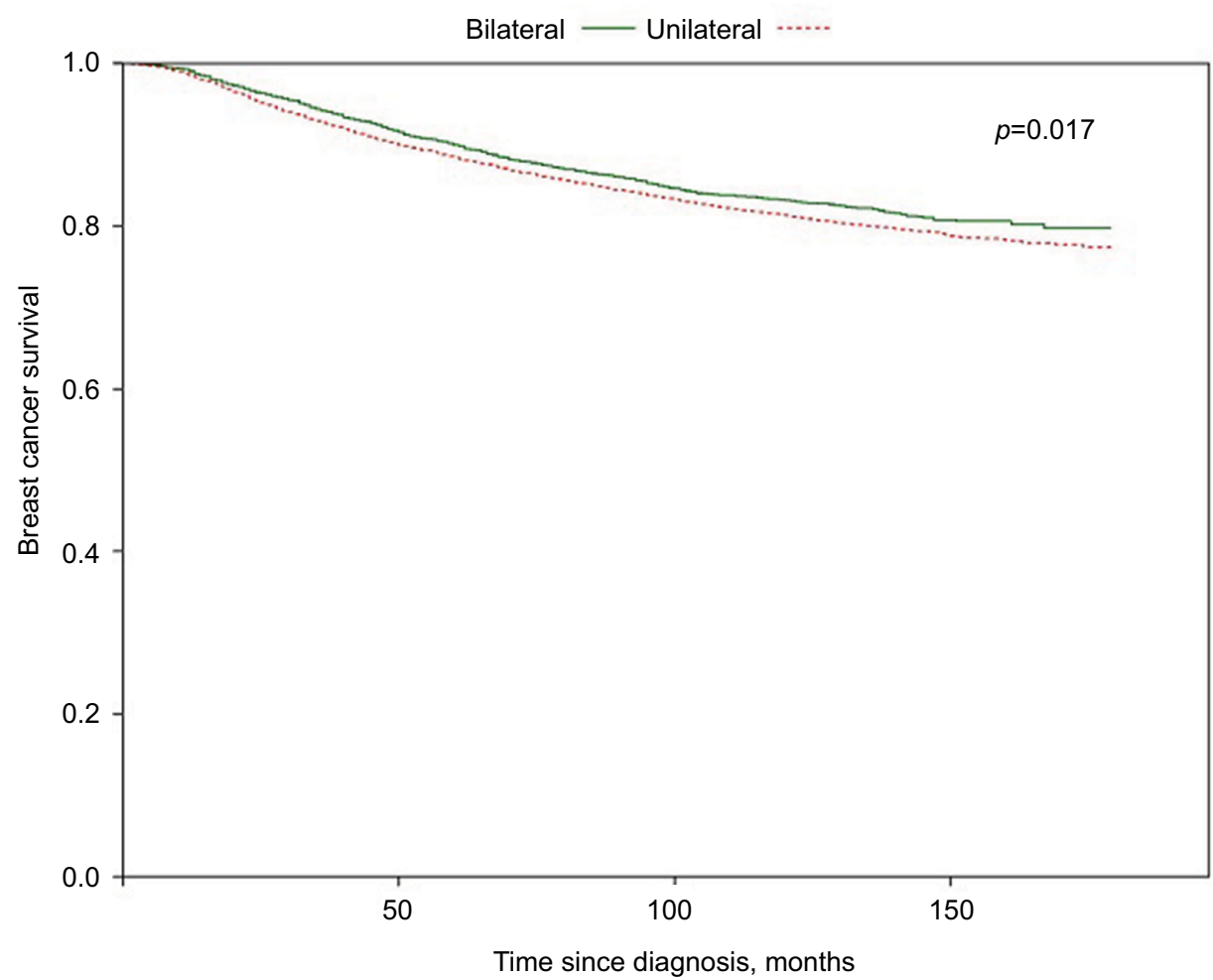

Figure I Kaplan-Meier survival curves comparing breast cancer-specific survival of patients who underwent unilateral mastectomy or bilateral mastectomy for unilateral breast cancer. 
Table 3 Cox proportional hazards model with adjustment for matching and additional covariates

\begin{tabular}{|c|c|c|c|}
\hline Variables & Category & $\begin{array}{l}\text { Hazard ratio and } 95 \% \\
\text { confidence limits }\end{array}$ & $p$-value \\
\hline Mastectomy & Bilateral vs unilateral & $0.92(0.83,1.02)$ & 0.109 \\
\hline \multirow[t]{3}{*}{ Race } & Black vs white & $\mathrm{I} .5(\mathrm{I} .35, \mathrm{I} .67)$ & $<0.0001$ \\
\hline & Other vs white & $0.97(0.83,1.15)$ & 0.7512 \\
\hline & Unknown vs white & $0.2(0.03, \mathrm{I} .37)$ & 0.101 \\
\hline Radiation & Radiation vs no radiation & $0.93(0.85,1.02)$ & 0.1134 \\
\hline Reconstruction & Reconstruction vs no reconstruction & $0.87(0.79,0.96)$ & 0.0074 \\
\hline \multirow[t]{3}{*}{ Receptor status (ER) } & Borderline vs negative & $0.47(0.17,1.28)$ & 0.1398 \\
\hline & Positive vs negative & $0.76(0.67,0.85)$ & $<0.0001$ \\
\hline & Unknown vs negative & $0.88(0.6, \mathrm{I} .3)$ & 0.5221 \\
\hline \multirow[t]{3}{*}{ Receptor status (PR) } & Borderline vs negative & I. $18(0.69,2.02)$ & 0.5399 \\
\hline & Positive vs negative & $0.71(0.64,0.8)$ & $<0.0001$ \\
\hline & Unknown vs negative & $0.82(0.56,1.19)$ & 0.2898 \\
\hline
\end{tabular}

Abbreviations: ER, estrogen receptor; PR, progesterone receptor.

contrast with our analysis of the national SEER database using matched cohorts, which did not show a statistically significant relative decrease in risk of cause-specific death. In our analysis, patients were restricted to a single histologic code, ductal carcinoma (8500), to reduce heterogeneity among tumors. Additionally, their analysis did not adjust for reconstruction status, which has also been shown to strongly associate with breast cancer death. ${ }^{18,20}$ Furthermore, for our model, we selected patients diagnosed during a limited time period from 1998 through 2002. Although this limits the number of patients in our cohorts, it allowed us to increase the length of follow-up, a critical issue because breast cancer surveillance is a life-long process. We chose this specific interval of years to allow for uniformity in staging according to the American Joint Committee on Cancer, 3rd edition, and to also minimize the impact of temporal changes in technology or chemotherapy which may affect outcomes. ${ }^{21}$

Two more recent studies have compared breast cancer death after bilateral mastectomy, unilateral mastectomy, or BCT. ${ }^{3,17}$ Kurian et al used the California Cancer Registry, a component registry of SEER, to show that patients who undergo bilateral mastectomy have similar hazard of breast cancer death when compared with patients who undergo BCT, but interestingly they found a significantly reduced hazard of breast cancer death when compared with patients undergoing unilateral mastectomy. ${ }^{17}$ Wong et al performed a similar analysis using the SEER database with similar results. ${ }^{3}$ However, the interpretation of these results is unclear because a three-way analysis was performed with bilateral mastectomy, unilateral mastectomy, and BCT. The inclusion of BCT in a comparison with unilateral and bilateral mastectomy leads to lack of distributional overlap for variables such as radiation therapy. Radiation is considered a standard part of the treatment regimen for BCT, but not for patients who receive mastectomy. By performing an analysis excluding
$\mathrm{BCT}$, we were able to directly compare unilateral and bilateral mastectomy, in which the general indications for radiation therapy remained similar. Direct comparison of unilateral and bilateral mastectomy suggests that breast cancer-specific death after bilateral mastectomy is not significantly reduced when compared with unilateral mastectomy.

\section{Limitations}

Our study has several limitations associated with a large database study. First, we were unable to account for variables that were not reported by the SEER database, including chemotherapy use and lymphovascular invasion..$^{22-24}$ Nevertheless, patients matched for the stage of disease would be expected to have the same indications for chemotherapy regardless of whether they undergo bilateral or unilateral mastectomy. We were also unable to account for other risk factors such as $B R C A$ status and family history. ${ }^{8}$ Furthermore, data accuracy is limited to reporting in patient charts and subsequent data abstraction..$^{25}$ Finally, we were unable to directly address comorbidities among patients who underwent bilateral or unilateral mastectomy; however, our cohorts were matched based on age.

\section{Conclusion}

Patients must feel comfortable with their choice of surgical therapy, from initial consultation to peri-operative and postoperative management and reconstruction. The decision to undergo bilateral mastectomy is likely multifactorial and strong associations have been shown with patient age, race, and even reconstruction status. ${ }^{2}$ Patients may choose to undergo bilateral mastectomy due to anxiety and perceptions regarding risk of contralateral breast cancer. ${ }^{11}$ In addition, patients may believe that bilateral mastectomy will improve reconstruction outcomes. ${ }^{11}$ Recently, a survey study found that breast surgeons remain uncomfortable with bilateral 
mastectomy due to ambiguity with oncologic outcomes and highlighted a need for further research. ${ }^{26}$ Although bilateral mastectomy may not offer patients a survival benefit, it may alleviate other patient concerns, and survival analysis may not provide a complete picture of the benefits of bilateral mastectomy. Nonetheless, given the risks associated with bilateral mastectomy and the costs associated with longer operative times and lengthier inpatient hospitalization, it is important to obtain objective outcome measures of bilateral mastectomy. ${ }^{13-15}$ In the present analysis, we showed that among patients with unilateral breast cancer, patients treated with bilateral mastectomy do not have a statistically or clinically significant reduction in breast cancer-specific death when compared with patients treated with unilateral mastectomy.

\section{Author contributions}

SA designed the analysis, reviewed the data, and wrote the manuscript; LP performed statistical analysis; JA designed the analysis, reviewed the data, wrote the manuscript. All authors contributed toward data analysis, drafting and revising the paper and agree to be accountable for all aspects of the work.

\section{Disclosure}

The authors report no other conflicts of interest in this work.

\section{References}

1. Tuttle TM, Jarosek S, Habermann EB, et al. Increasing rates of contralateral prophylactic mastectomy among patients with ductal carcinoma in situ. J Clin Oncol.2009;27(9):1362-1367.

2. Agarwal S, Kidwell KM, Kraft CT, et al. Defining the relationship between patient decisions to undergo breast reconstruction and contralateral prophylactic mastectomy. Plast Reconstr Surg. 2015;135(3):661-670.

3. Wong SM, Freedman RA, Sagara Y, Aydogan F, Barry WT, Golshan M. Growing use of contralateral prophylactic mastectomy despite no improvement in long-term survival for invasive breast cancer. Ann Surg. 2017;265(3):581-589.

4. Abbott A, Rueth N, Pappas-Varco S, Kuntz K, Kerr E, Tuttle T. Perceptions of contralateral breast cancer: an overestimation of risk. Ann Surg Oncol. 2011;18(11):3129-3136.

5. Arrington AK, Jarosek SL, Virnig BA, Habermann EB, Tuttle TM. Patient and surgeon characteristics associated with increased use of contralateral prophylactic mastectomy in patients with breast cancer. Ann Surg Oncol. 2009;16(10):2697-2704.

6. Ashfaq A, McGhan LJ, Pockaj BA, et al. Impact of breast reconstruction on the decision to undergo contralateral prophylactic mastectomy. Ann Surg Oncol. 2014;21(9):2934-2940.

7. Fayanju OM, Stoll CR, Fowler S, Colditz GA, Margenthaler JA. Contralateral prophylactic mastectomy after unilateral breast cancer: a systematic review and meta-analysis. Ann Surg. 2014;260(6):1000-1010.
8. Hawley ST, Jagsi R, Morrow M, et al. Social and clinical determinants of contralateral prophylactic mastectomy. JAMA Surg. 2014;149(6):582-589.

9. King TA, Sakr R, Patil S, et al. Clinical management factors contribute to the decision for contralateral prophylactic mastectomy. J Clin Oncol. 2011;29(16):2158-2164.

10. Morrow M. Prophylactic mastectomy of the contralateral breast. Breast. 2011;20(Suppl 3):S108-S110.

11. Soran A, Kamali Polat A, Johnson R, McGuire KP. Increasing trend of contralateral prophylactic mastectomy: what are the factors behind this phenomenon? Surgeon. 2014;12(6):316-322.

12. Yi M, Hunt KK, Arun BK, et al. Factors affecting the decision of breast cancer patients to undergo contralateral prophylactic mastectomy. Cancer Prevent Res. 2010;3(8):1026-1034.

13. Miller ME, Czechura T, Martz B, et al. Operative risks associated with contralateral prophylactic mastectomy: a single institution experience. Ann Surg Oncol. 2013;20(13):4113-4120.

14. Silva AK, Lapin B, Yao KA, Song DH, Sisco M. The effect of contralateral prophylactic mastectomy on perioperative complications in women undergoing immediate breast reconstruction: a NSQIP analysis. Ann Surg Oncol. 2015;22(11):3474-3480.

15. Osman F, Saleh F, Jackson TD, Corrigan MA, Cil T. Increased postoperative complications in bilateral mastectomy patients compared to unilateral mastectomy: an analysis of the NSQIP database. Ann Surg Oncol. 2013;20(10):3212-3217.

16. Bedrosian I, Hu CY, Chang GJ. Population-based study of contralateral prophylactic mastectomy and survival outcomes of breast cancer patients. J Natl Cancer Inst. 2010;102(6):401-409.

17. Kurian AW, Lichtensztajn DY, Keegan TH, Nelson DO, Clarke CA, Gomez SL. Use of and mortality after bilateral mastectomy compared with other surgical treatments for breast cancer in California, 1998-2011. JAMA.2014;312(9):902-914.

18. Agarwal J, Agarwal S, Pappas L, Neumayer L. A population-based study of breast cancer-specific survival following mastectomy and immediate or early-delayed breast reconstruction. Breast J. 2012;18(3): 226-232.

19. Agarwal S, Pappas L, Neumayer L, Kokeny K, Agarwal J. Effect of breast conservation therapy vs mastectomy on disease-specific survival for early-stage breast cancer. JAMA Surg. 2014;149(3):267-274.

20. Agarwal S, Liu JH, Crisera CA, Buys S, Agarwal JP. Survival in breast cancer patients undergoing immediate breast reconstruction. Breast J. 2010;16(5):503-509.

21. Miyashita M, Tada H, Suzuki A, et al. Minimal impact of postmastectomy radiation therapy on locoregional recurrence for breast cancer patients with 1 to 3 positive lymph nodes in the modern treatment era. Surg Oncol. 2017;26(2):163-170.

22. Warren JL, Harlan LC, Fahey A, et al. Utility of the SEERMedicare data to identify chemotherapy use. Med Care. 2002;40(8 Suppl):IV-55-61.

23. Zhang S, Zhang D, Gong M, Wen L, Liao C, Zou L. High lymphatic vessel density and presence of lymphovascular invasion both predict poor prognosis in breast cancer. BMC Cancer. 2017;17(1):335.

24. Zhang S, Zhang D, Yi S, et al. The relationship of lymphatic vessel density, lymphovascular invasion, and lymph node metastasis in breast cancer: a systematic review and meta-analysis. Oncotarget. 2017;8(2): 2863-2873.

25. Talia J, Agarwal S, Momoh AO, Wilkins EG, Kozlow JH. The validity of hospital discharge data for autologous breast reconstruction research. Plastic Reconstr Surg. 2015;135(2):368-374.

26. Bellavance E, Peppercorn J, Kronsberg S, et al. Surgeons' perspectives of contralateral prophylactic mastectomy. Ann Surg Oncol. 2016;23(9):2779-2787. 


\section{Publish your work in this journal}

Cancer Management and Research is an international, peer-reviewed open access journal focusing on cancer research and the optimal use of preventative and integrated treatment interventions to achieve improved outcomes, enhanced survival and quality of life for the cancer patient. The manuscript management system is completely online and includes a very quick and fair peer-review system, which is all easy to use. Visit http://www.dovepress.com/testimonials.php to read real quotes from published authors.

Submit your manuscript here: https://www.dovepress.com/cancer-management-and-research-journal 